\title{
Tensile and fatigue properties, machinability and machined surface roughness of $\mathrm{Al}-\mathrm{Si}-\mathrm{Cu}$ alloys
}

Sebastian Balos ${ }^{1}$, Dragan Rajnovic ${ }^{1}$, Leposava Sidjanin ${ }^{1}$, Borislav Savkovic $^{1}$, Pavel Kovac ${ }^{1}$, Petar Janjatovic ${ }^{1}$

\author{
${ }^{1}$ Department of Production Engineering, Faculty of Technical Sciences, University of Novi Sad, Trg Dositeja Obradovi- \\ ca 6, Novi Sad, Voivodina, Serbia. \\ e-mail: sebab@uns.ac.rs,draganr@uns.ac.rs, lepas@uns.ac.rs, savkovic@uns.ac.rs,pkovac@uns.ac.rs, \\ janjatovic@uns.ac.rs
}

\begin{abstract}
In this paper, the aim was to determine if ASC91 $(9 \% \mathrm{Al}, 1 \% \mathrm{Cu})$ could be replaced with ASC73 $(7 \% \mathrm{Al}$, $3 \% \mathrm{Cu}$ ) aluminium alloy, with presumably improved machinability due to lower silicon content (9 to $7 \%$ ) and retained mechanical properties due to a higher copper content (1 to $3 \%)$. The test samples were excised from cylinder heads produced by the lost-foam casting technique in industrial conditions. The tensile properties (proof strength, ultimate tensile strength, elongation and modulus of elasticity), fatigue performance, microstructure and machinability of two as-cast aluminium alloys were examined. The results of the fatigue tests were statistically analyzed using the stair-case method described in the UNI 3964 standard. Tensile properties of the ASC91 were higher, while fatigue properties were higher in the ASC73 alloy. The resultant force was lower for the ASC73, while roughness was lower for the ASC73 alloy, if the feed per tooth is higher than $0.21 \mathrm{~mm} / \mathrm{t}$. Two main factors that influence such behaviour are the amount of eutectic silicon and the $\alpha$-solid solution adhesion to the cutting tool.
\end{abstract}

Keywords: aluminium cast alloys; tensile properties; fatigue; machinability; roughness.

\section{INTRODUCTION}

The selection of casting alloys for the automotive industry, where aluminium and silicon alloys have a very important role, strongly depends on a number of factors, such as the service requirements and technological factors required to achieve the economy of processing, as stated by Dwivedi et al. [1]. Service requirements may be achieved by adequate mechanical properties (modulus of elasticity, strength, fatigue life), while technological properties depend on the method of fabrication and, in the majority of cases, machining. Pathak and Tiwari [2] reported that more than $80 \%$ of fabricated work pieces require machining before they are ready for use. Therefore, it is necessary to obtain castings with as much dimensional accuracy as possible so that machining is reduced to the lowest extent.

It is known that pure aluminium adheres to the tool tip, forming a built-up edge. The build-up edge transfers heat to the tool that may affect both the tool life and the work piece quality (poor surface finish and machining accuracy). However, typical aluminium casting alloys contain silicon, which may occur as primary silicon particles in hypereutectic alloys (over $12 \%$ of silicon) and as a phase that forms the eutectic (eutectic silicon), as reported by Kamiya et al. [3]. Liu and Chou [4] as well as Kamiya et al [3] reported that extremely hard silicon particles contribute to severe tool wear which greatly reduces the tool life. There are numerous attempts to improve tool wear by reducing the primary silicon crystal size. Youn et al. [5] and Feng et al. [6] reported the use of ultrasound vibration, electromagnetic stirring was applied by Lu et al. [7], while Anuradee et al. [8] applied electromagnetic vibration. Beside mechanical refinements, the addition of alloying elements, such as phosphorus may refine the primary silicon as well. Chang et al. [9] and Yi and Zhang [10] found that the addition of rare elements such as cesium and lanthanum improves the machinability. A traditional way of providing an increased machinability (lower cutting forces and surface roughness) is to decrease the silicon content in an alloy. However, this has an adverse effect on alloy's mechanical properties. An alternative may be to apply a relatively low silicon content combined with the addition of copper. 
Dwivedi et al. [1] reported that low silicon alloys with copper after heat treatment may have equal or better machinability than those with high silicon content and copper.

The specific objective of this study is to determine the influence of using a decreased silicon content and increasing the copper content in the hypoeutectic lost-foam cast aluminium alloys, specifically the effects on tensile and fatigue properties, as well as the machining properties and surface roughness.

\section{MATERIALS AND METHODS}

The test samples were excised from cylinder heads produced by the lost-foam casting technique in industrial conditions. The foam patterns were prepared using injection moulding and gluing. The patterns were then assembled into a foam tree and coated with ceramic slurry, which was subsequently heated in a furnace to produce a refractory ceramic shell. The coated foam tree was then placed in a sand box and the loose sand was poured to fill the box around the foam tree. Afterwards, the molten metal obtained in an induction furnace was poured. Castings were removed from the moulds upon cooling to room temperature. Two aluminium alloys were produced, with the chemical compositions given in Table 1, referred to as ASC73 and ASC91 hereafter.

Table 1: Chemical composition.

\begin{tabular}{|c|c|c|c|c|c|c|c|c|c|}
\hline Alloy & $\mathrm{Cu}$ & $\mathrm{Mn}$ & $\mathrm{Mg}$ & $\mathrm{Si}$ & $\mathrm{Fe}$ & $\mathrm{Zn}$ & $\mathrm{Ti}$ & $\mathrm{Ni}$ & $\mathrm{Al}$ \\
\hline ASC91 & 0.92 & 0.18 & 0.35 & 9.20 & 0.27 & 0.12 & 0.12 & - & balance \\
\hline ASC73 & 3.22 & 0.20 & 0.30 & 6.58 & 0.38 & 0.38 & 0.19 & 0.055 & balance \\
\hline
\end{tabular}

The mechanical properties (tensile strength, proof strength, elongation, modulus of elasticity and fatigue resistance), microstructural properties and machining parameters were determined for both alloys. The tensile strength, proof strength and elongation were found on the basis of 30 specimens overall, machined from the peripheral part and from the central part of the cylinder head. The modulus of elasticity was determined on the basis of three measurements. Tensile strength, proof strength, elongation and modulus of elasticity were tested on the VEB ZDM 5/91 mechanical tensile testing machine. The tensile test specimens had a diameter of $8 \mathrm{~mm}$ and a gauge length of $40 \mathrm{~mm}$, while the modulus of the elasticity specimens had a diameter of $8 \mathrm{~mm}$ and a gauge length of $100 \mathrm{~mm}$. Tensile elongation was determined by manual measurement from the fractured specimens, while modulus of elasticity elongations were measured by a mechanical extensiometer.

Fatigue tests had been performed in compliance with the UNI 3964 standard on the Schenck Hydropuls PS250B dynamic testing machine, on 25 specimens. The testing conditions were: the number of cycles $\mathrm{N}=10000000$, symmetrical dynamic load $\mathrm{R}=-1$, temperature of testing $\mathrm{T}=130^{\circ} \mathrm{C}$, starting amplitude stress $=$ $40 \mathrm{MPa}$ and stair-case step $=10 \mathrm{MPa}$. The results of the fatigue tests were statistically analyzed using the stair-case method described in the UNI 3964 standard. Equations used for the fatigue testing, were as following:

$$
\begin{aligned}
& \sigma_{D(50 \%)}=\sigma_{0}+d \cdot(A / N+0.5) \\
& \sigma_{D(10 \%)}=\sigma_{D(50 \%)}+1.28 \cdot x \\
& \sigma_{D(90 \%)}=\sigma_{D(50 \%)}-1.28 \cdot x \\
& x=1.62 \cdot d \cdot\left(\left(N \cdot B-A^{2}\right)+0.029\right)
\end{aligned}
$$

where $\sigma_{0}=30 \mathrm{MPa}$, minimal amplitude stress (stress at level $\mathrm{i}=0$ ) and $d=10 \mathrm{MPa}$, stair-case step. $\mathrm{N}$, A, B - factors found experimentally from the number of non-fractured specimens (n) and the stress levels (i): $\mathrm{N}=\Sigma \mathrm{n} ; \mathrm{A}=\Sigma \mathrm{i} \cdot \mathrm{n} ; \mathrm{B}=\Sigma \mathrm{i}^{2} \cdot \mathrm{n}$.

Metallographic examinations were conducted in order to determine microstructure and to examine fracture surfaces. The microstructure was examined on specimens prepared in accordance to the standard metallographic preparation technique: grinding (sandpaper, grit 220 to 2000), polishing (diamond suspensions with $6,3,1$ and $1 / 4 \mu \mathrm{m}$ particle size) and etching with $1 \% \mathrm{HF}$ alcohol solution. The specimens were examined by using Leitz Orthoplan light microscope, as well as JEOL JSM-6460LV scanning electron microscope (SEM), operating at $20 \mathrm{kV}$. To identify the intermetallic phases, energy-dispersive X-ray spectroscopy (EDX) was performed, using an Oxford Instruments INCA Microanalysis system. For more comprehensive quantitative characterization of the microstructure (secondary dendrite arm spacing - SDAS, and area 
fractions of eutectic and intermetallics) the JMicroVision 1.2.7 Image Analysis Software was used. The Silicon Modification Level (SML) determination was performed by comparison with the AFS Chart [11].

Machinability was determined by quantifying the maximum roughness height $\left(\mathrm{R}_{\max }\right)$, ten point mean roughness $\left(\mathrm{R}_{\mathrm{z}}\right)$, and resultant force $\left(\mathrm{F}_{\mathrm{R}}\right)$ in relation to the depth of cut (a) and the feed per tooth $\left(\mathrm{s}_{1}\right)$. Vertical milling machine Prvomajska FAS-GVK-3 was equipped with a milling head with interchangeable cutting inserts. In addition, a Kistler 9257A sensor measurement system and a Kistler CA-500 amplifier were used, as well as an ED429-UP dial-up panel for connecting the module with the actual acquisition process and an ED428 A/D converter. The model of the acquisition system for measuring the cutting force in face milling is shown in Figure 1.

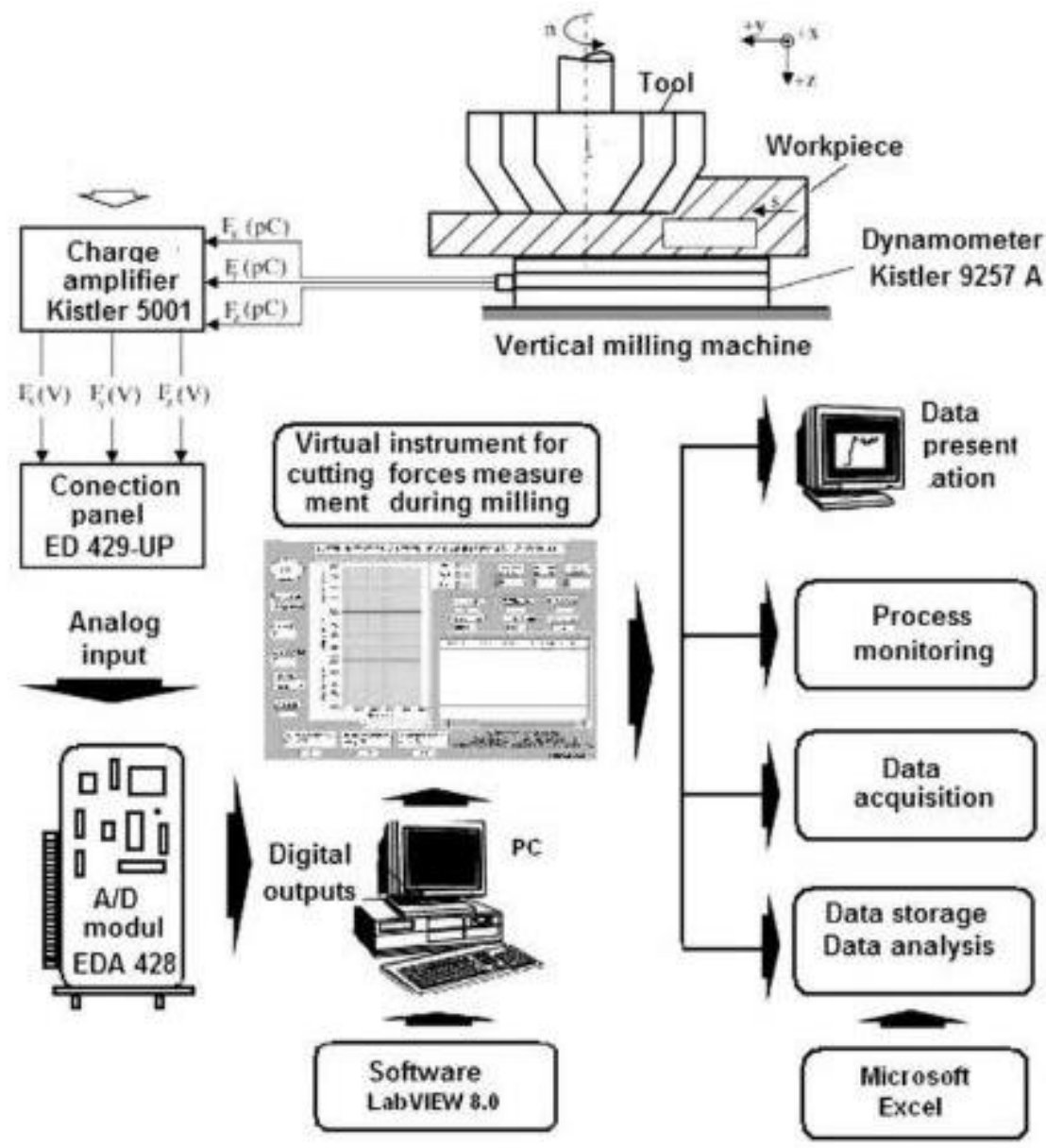

Figure 1: The acquisition system for measuring the cutting force in face milling.

In this setup, the cutting force was represented by the resultant force, calculated by using the following equation:

$$
F_{R}=\sqrt{ }\left(F_{x}^{2}+F_{y}^{2}+F z^{2}\right)
$$

where $F_{R}$ is the resultant force, while $F_{x}, F_{y}$ and $F_{z}$ are the forces along the three axes.

Surface texture parameters, such as maximum roughness height and mean roughness height of machined surface were tested with Mitutoyo Surftest SJ-301 profilometer with $5 \mu \mathrm{m}$ radius diamond stylus. Roughness parameters were measured at $3.7 \mathrm{~mm}$ measurement length. To determine the resultant cutting force and roughness in relation to the depth of cut and the feed per tooth, a two-factorial experimental design was applied.

Dry machining tests were done on $8 \mathrm{~mm}$ square specimens, $50 \mathrm{~mm}$ long, with the following parameters: rotation speed $560 \mathrm{~min}^{-1}$; cutting speed $3.665 \mathrm{~m} / \mathrm{s}$ and by using $\varnothing 125 \mathrm{~mm}$ milling tool. Factors were varied at three-value levels: the depth of cut had the following values 1;1.41;2 mm, while the feed per tooth 
was varied as $0.112 ; 0.178 ; 0.285 \mathrm{~mm} / \mathrm{t}$. In accordance to these input values, the functional dependence was found, in the form of a degree function of the first-order mathematical model, Eq. (6):

$$
R=c \cdot f_{1}^{\beta_{1}} \cdot f_{2}^{\beta_{2}}
$$

where $c$ is constant, $f_{1}, f_{2}$ are variables and $\beta_{1,} \beta_{2}$ are variable exponents.

By taking the logarithm of Eq. (6), Eq. (7) is obtained:

$$
\ln R=\ln C+\beta_{1} \cdot \ln f_{1}+\beta_{2} \cdot \ln f_{2}
$$

If $\ln R=y ; \ln f_{1}=x_{1}$ and $\ln f_{2}=x_{2}$, the Eq. (7) may be rewritten as:

$$
y=\beta_{\mathrm{o}}+\beta 1 \cdot x_{1}+\beta_{2} \cdot x_{2}
$$

Afterwards, a regression analysis was performed and dependence equations for $F_{R}, R_{\max }$ and $R_{z}$ were obtained in relation to the depth of cut and the feed per tooth. The obtained trends were used to evaluate ASC73 and ASC91 aluminium alloys machinability at different depths of cut and feeds per tooth.

\section{RESULTS}

\subsection{Tensile properties}

The tensile testing results are shown in Table 2. ASC91 aluminium alloy possesses considerably higher modulus of elasticity (E), proof strength (PS), ultimate tensile strength (UTS) and elongation, compared to ASC73 alloy. Furthermore, it can be seen that the minimum results obtained for ASC91 alloy are higher (E, PS, UTS) than those of ASC73 alloy. Standard deviations in the tensile testing results of ASC73 alloy are lower than those of ASC91 alloy if PS and elongation are considered, however, in terms of UTS, the standard deviation in ASC91 alloy is marginally lower.

Table 2: Tensile testing results.

\begin{tabular}{|l|l|c|c|c|c|}
\hline & & $\begin{array}{l}\text { Modulus of elas- } \\
\text { ticity E [GPa] }\end{array}$ & $\begin{array}{l}\text { Proof strength } \\
\text { Rp0.2\% [MPa] }\end{array}$ & $\begin{array}{l}\text { Ultimate tensile } \\
\text { strength Rm [MPa] }\end{array}$ & $\begin{array}{l}\text { Elongation } \\
\text { A5 [\%] }\end{array}$ \\
\hline \multirow{3}{*}{ ASC91 } & Average & 77.0 & 208.5 & 246.2 & 2.2 \\
\cline { 2 - 6 } & Standard deviation & 5.6 & 9.3 & 6.2 & 0.3 \\
\cline { 2 - 6 } & Minimum value & 75.6 & 192.6 & 236.2 & 1.5 \\
\cline { 2 - 6 } & Maximum value & 79.1 & 225.0 & 259.3 & 3.0 \\
\hline \multirow{3}{*}{ ASC73 } & Average & 70.5 & 143.6 & 161.7 & 0.2 \\
\cline { 2 - 6 } & Standard deviation & 1.2 & 7.1 & 6.7 & 0.5 \\
\cline { 2 - 6 } & Minimum value & 69.8 & 131.6 & 150.3 & 1.5 \\
\cline { 2 - 6 } & Maximum value & 72.0 & 155.7 & 172.2 & \\
\hline
\end{tabular}

\subsection{Fatigue}

The results that show the fatigue performance of ASC91 and ASC73 aluminium alloys are shown in Tables 3 and 4. In Table 3, statistical representation is shown, while in Table 4, the results of stair-case method of determining fatigue resistance are shown. It can be seen that although the conventional fatigue limit at $50 \%$ probability of non-fracture in both alloys is almost similar, fatigue limits at 10 and $90 \%$ probability of nonfracture varies considerably, Table 4. Fatigue limit of the ASC91 alloy is higher if the probability of survival is set to $90 \%$ (the lower limit in S-N curve), while the fatigue limit of ASC73 is higher if the probability of survival is set to $10 \%$ (the upper limit in S-N curve). That means, ASC91 alloy is has a lower $\sigma_{D}$ if the fatigue limit is set at $10 \%$ and higher $\sigma_{\mathrm{D}}$ if fatigue limit is set at $90 \%$, indicating that ASC91 has a narrower range of $\sigma_{\mathrm{D}}$ compared to ASC73, but the $50 \%$ value in ASC91 is slightly lower than that of the ASC73 alloy. 
Table 3: Statistical representation of results (x-fractured, o-not fractured): $i$ - stress levels, $n$ - number of not fractured samples at given level).

\begin{tabular}{|c|c|c|c|c|c|c|c|c|c|c|c|c|}
\hline \multirow{2}{*}{$\begin{array}{c}\sigma \mathrm{a} \\
{[\mathrm{MPa}}\end{array}$} & \multicolumn{6}{|c|}{ ASC91 } & \multicolumn{6}{|c|}{ ASC73 } \\
\hline & $\mathrm{x}$ & o & i & $\mathrm{n}$ & $\mathrm{i} \cdot \mathrm{n}$ & $\mathrm{i}^{2} \cdot \mathrm{n}$ & $\mathrm{x}$ & o & i & $\mathrm{n}$ & $\mathrm{i} \cdot \mathrm{n}$ & $\mathrm{i}^{2} \cdot \mathrm{n}$ \\
\hline 70 & 1 & 0 & 4 & 0 & 0 & 0 & 1 & 0 & 4 & 0 & 0 & 0 \\
\hline 60 & 5 & 1 & 3 & 1 & 3 & 9 & 5 & 2 & 3 & 2 & 6 & 18 \\
\hline 50 & 5 & 5 & 2 & 5 & 10 & 20 & 3 & 6 & 2 & 6 & 12 & 24 \\
\hline 40 & 1 & 6 & 1 & 6 & 6 & 6 & 2 & 4 & 1 & 4 & 4 & 4 \\
\hline 30 & 0 & 1 & 0 & 1 & 0 & 0 & 0 & 2 & 0 & 2 & 0 & 0 \\
\hline & $\Sigma=12$ & $\Sigma=13$ & & $\mathrm{~N}=13$ & $\mathrm{~A}=19$ & $\mathrm{~B}=35$ & $\Sigma=11$ & $\Sigma=14$ & & $\mathrm{~N}=14$ & $\mathrm{~A}=22$ & $\mathrm{~B}=46$ \\
\hline
\end{tabular}

Table 4: Results of the stair-case method.

\begin{tabular}{|c|c|c|c|}
\hline & $\begin{array}{c}\text { Fatigue limit at 10\% prob- } \\
\text { ability of non-fracture } \\
\sigma_{\mathrm{D}}(10 \%)[\mathrm{MPa}]\end{array}$ & $\begin{array}{c}\text { Fatigue limit at 50\% prob- } \\
\text { ability of non-fracture } \\
\sigma_{\mathrm{D}}(50 \%)[\mathrm{MPa}]\end{array}$ & $\begin{array}{c}\text { Fatigue limit at 90\% prob- } \\
\text { ability of non-fracture } \\
\sigma_{\mathrm{D}}(90 \%)[\mathrm{MPa}]\end{array}$ \\
\hline ASC91 & 61.76 & 49.61 & 37.47 \\
\hline ASC73 & 68.22 & 50.75 & 33.20 \\
\hline
\end{tabular}

\subsection{Microstructure}

The microstructure of the ASC91 and ASC73 aluminium alloys are shown in Figure 2. The microstructure consists of $\alpha$-solid solution, an interdendritic network of eutectic silicon ( $\alpha$-solid solution and silicon particles), intermetallic phases, and some porosity, Table 5. The silicon modification level (SML) is higher for the ASC91 alloy where the rounded particles of Si could be generally observed (SML - level 5). In the case of the ASC73 alloy the SML is lower, characterized by the angular appearance of the eutectic Si particles (SML - level 3). Furthermore, in the ASC73 alloy un-modified Si, coarse and "blocky" shaped particles (level 1) are present. Also, the amount of eutectic is reduced in the ASC73 alloy, while the presence of intermetallic phases is increased. The observed intermetallic phases in the ASC73 alloy generally have a "blocky" appearance, while in the ASC91 alloy the intermetallic phases have a "Chinese" script morphology. 


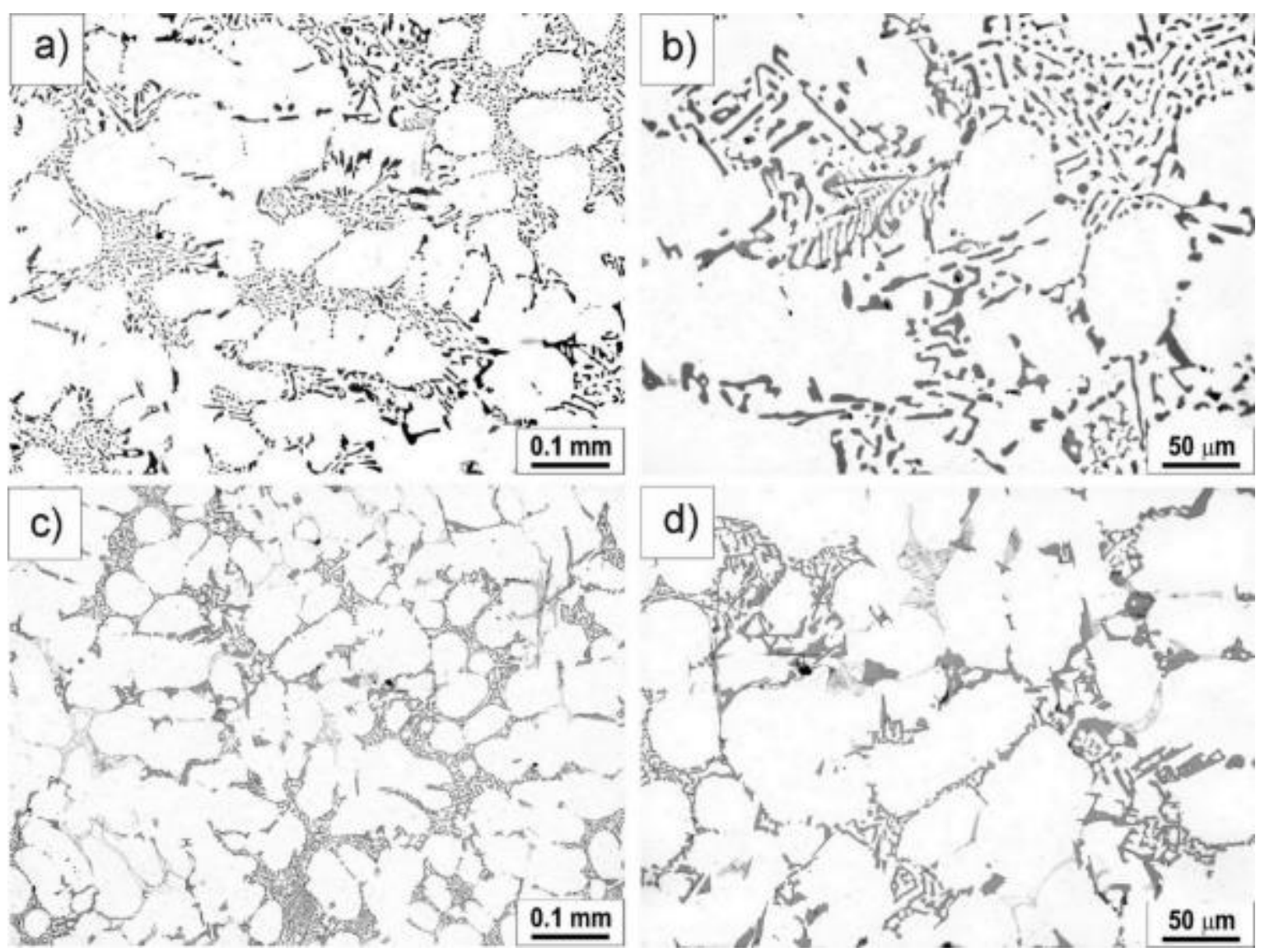

Figure 2: Microstructure: a,b) ASC91; c,d) ASC73 alloy.

Table 5: Quantitative evaluation of microstructure.

\begin{tabular}{|l|c|c|}
\hline & ASC91 & ASC73 \\
\hline SDAS (secondary dendrite arm spacing) $\pm \mathrm{SD}^{*}[\mu \mathrm{m}]$ & $51.5 \pm 15.6$ & $43.9 \pm 9.3$ \\
\hline$\alpha$-solution (without eutectic) $\pm 95 \% \mathrm{CI}^{* *}[\%]$ & $51.8 \pm 5.5$ & $62.7 \pm 2.6$ \\
\hline Eutectic $(\alpha+\mathrm{Si}) \pm 95 \% \mathrm{CI} * *[\%]$ & $43.9 \pm 4.5$ & $24.1 \pm 5.2$ \\
\hline Si particles (in eutectic) $\pm 95 \% \mathrm{CI}^{* *}[\%]$ & $11.5 \pm 0.1$ & $8.7 \pm 2.4$ \\
\hline Complex intermetallic phases $\pm 95 \% \mathrm{CI}^{* *}[\%]$ & $3.7 \pm 1.4$ & $3.4 \pm 0.7$ \\
\hline $\mathrm{Al}_{2} \mathrm{Cu} \pm 95 \% \mathrm{CI}^{* *}[\%]$ & - & $7.9 \pm 3.7$ \\
\hline Porosity $\pm 95 \% \mathrm{CI} * * \%]$ & $1.5 \pm 0.7$ & $1.8 \pm 0.9$ \\
\hline SML (silicon modification level) & level 5 & level 3 \\
& & (some level 1) \\
\hline
\end{tabular}

* standard deviation

** $95 \%$ confidence interval in accordance with ASTM E1245-03 (2008)

The EDX analysis revealed the chemical composition of the intermetallic phases, Figures 3 and 4, as well as Tables 6 and 7. In Figure 3 and Table 6, it can be seen that three different complex intermetallic phases are present in the ASC91 alloy: $\mathrm{AlCuFeMnSi}, \mathrm{Al}_{5} \mathrm{Cu}_{2} \mathrm{Mg}_{8} \mathrm{Si}_{6}$ and $\mathrm{Al}_{15}(\mathrm{Fe}, \mathrm{Mn})_{3} \mathrm{Si}_{2}$ (all similarly etched grey-brown, Figure 2b) [12-14]. On the other hand, in the ASC73 alloy (Figure 4, Table 7), two intermetallic phases were identified: $\mathrm{Al}_{2} \mathrm{Cu}$ (etched light grey, Figure 2b) and complex $\mathrm{AlCuFeMnSi}$ (etched brown, Figure 2d). [12-14]. 


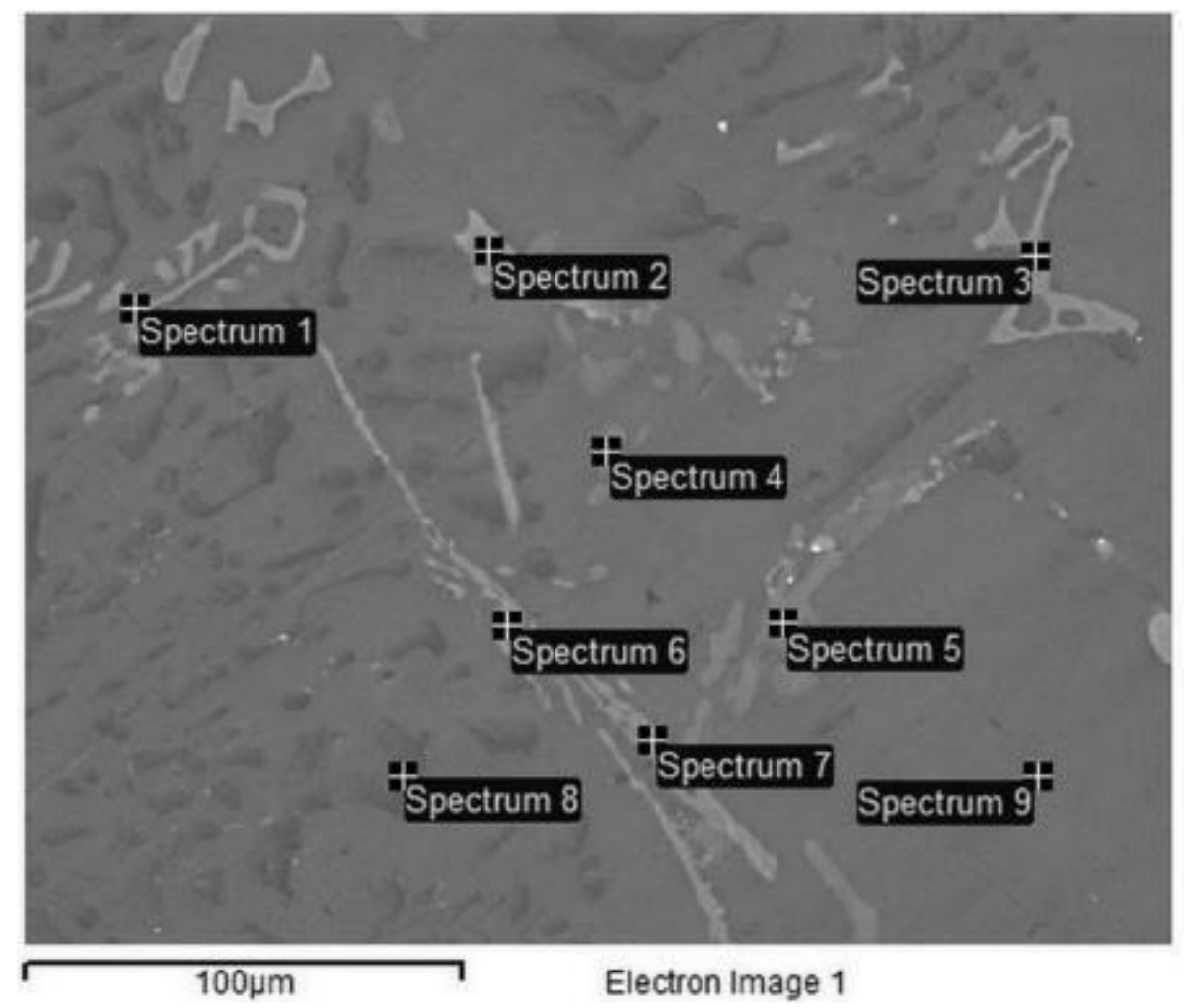

Figure 3: Intermetallic phases in ASC91 alloy

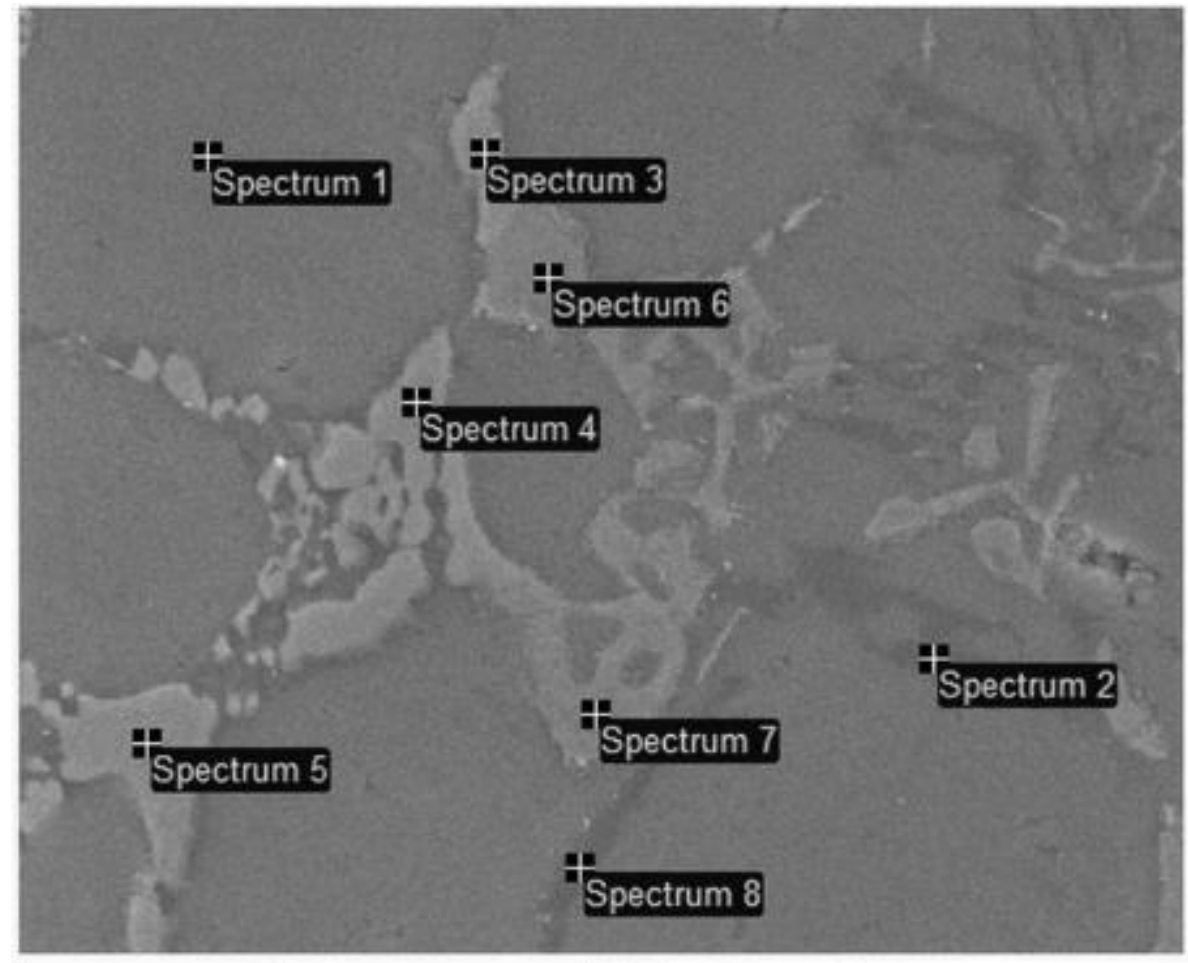

$80 \mu \mathrm{m}$

Electron Image 1

Figure 4: Intermetallic phases in ASC73 alloy. 
Table 6: Chemical composition of intermetallic phases in ASC91 alloy, corresponding to Figure 3

\begin{tabular}{|c|c|c|c|c|c|c|c|}
\hline & $\mathrm{Al}$ & $\mathrm{Si}$ & $\mathrm{Cu}$ & $\mathrm{Mn}$ & $\mathrm{Fe}$ & $\mathrm{Mg}$ & Phase identification \\
\hline Spectrum 1 & 71.94 & 8.58 & 2.83 & 6.54 & 10.12 & & $\mathrm{AlCuFeMnSi}$ \\
\hline Spectrum 2 & 54.99 & 8.88 & 9.24 & 4.31 & 22.58 & & $\mathrm{AlCuFeMnSi}$ \\
\hline Spectrum 3 & 68.38 & 9.11 & 3.22 & 7.44 & 11.85 & & $\mathrm{AlCuFeMnSi}$ \\
\hline Spectrum 4 & 32.70 & 28.78 & 15.62 & & & 22.90 & $\mathrm{Al}_{5} \mathrm{Cu}_{2} \mathrm{Mg}_{8} \mathrm{Si}_{6}$ \\
\hline Spectrum 5 & 20.29 & 32.99 & 18.45 & & & 28.28 & $\mathrm{Al}_{5} \mathrm{Cu}_{2} \mathrm{Mg}_{8} \mathrm{Si}_{6}$ \\
\hline Spectrum 6 & 60.86 & 8.24 & 6.27 & 6.48 & 18.15 & & $\mathrm{AlCuFeMnSi}$ \\
\hline Spectrum 7 & 57.72 & 16.82 & 0.37 & 4.58 & 20.52 & & $\mathrm{Al}_{15}\left(\mathrm{Fe}, \mathrm{Mn}_{3} \mathrm{Si}_{2}\right.$ \\
\hline Spectrum 8 & 45.57 & 53.40 & 1.03 & & & & $\mathrm{Si} \mathrm{particles}$ \\
\hline Spectrum 9 & 96.41 & 1.53 & 2.05 & & & & $\alpha-$ solid solution \\
\hline
\end{tabular}

Table 7: Chemical composition of intermetallic phases in ASC73 alloy, corresponding to Figure 4.

\begin{tabular}{|l|c|c|c|c|c|c|}
\hline & $\mathrm{Al}$ & $\mathrm{Si}$ & $\mathrm{Cu}$ & $\mathrm{Mn}$ & $\mathrm{Fe}$ & Phase identification \\
\hline Spectrum 1 & 97.21 & 1.67 & 1.12 & & & $\alpha$ - solid solution \\
\hline Spectrum 2 & 7.61 & 91.85 & 0.54 & & & $\mathrm{Si} \mathrm{particles}$ \\
\hline Spectrum 3 & 50.61 & 1.10 & 48.29 & & & $\mathrm{Al}_{2} \mathrm{Cu}$ \\
\hline Spectrum 4 & 48.74 & 13.75 & 37.51 & & & $\mathrm{Al}_{2} \mathrm{Cu}$ \\
\hline Spectrum 5 & 48.33 & 0.83 & 51.87 & & & $\mathrm{Al}_{2} \mathrm{Cu}$ \\
\hline Spectrum 6 & 54.36 & 9.72 & 6.98 & 8.14 & 20.80 & $\mathrm{AlCuFeMnSi}^{-12}$ \\
\hline Spectrum 7 & 57.61 & 10.03 & 4.64 & 9.20 & 18.52 & $\mathrm{AlCuFeMnSi}$ \\
\hline Spectrum 8 & 86.21 & 10.84 & 2.95 & & & $\alpha$ - solid solution+Si particle \\
\hline
\end{tabular}

\subsection{Fracture surfaces}

The fracture morphology of tensile tested specimens is shown in Figures. 5, 6 and 7, 8, for the ASC91 and ASC73 alloys, respectively. As it can be seen, the fracture mode in the ASC91 alloy is brittle, Figure 5. Furthermore, at the fracture surface dendritic microporosity is observed, Figure 6. The largest observed micropore in the ASC91 alloy has dimensions of $0.443 \times 0.246 \mathrm{~mm}$. As in ASC91, the fracture mode of ASC73 is brittle and some dendrite microporosity is observed as well. The largest observed micropore in the ASC73 alloy has dimensions of $0.555 \times 0.325 \mathrm{~mm}$, Figure 8 .
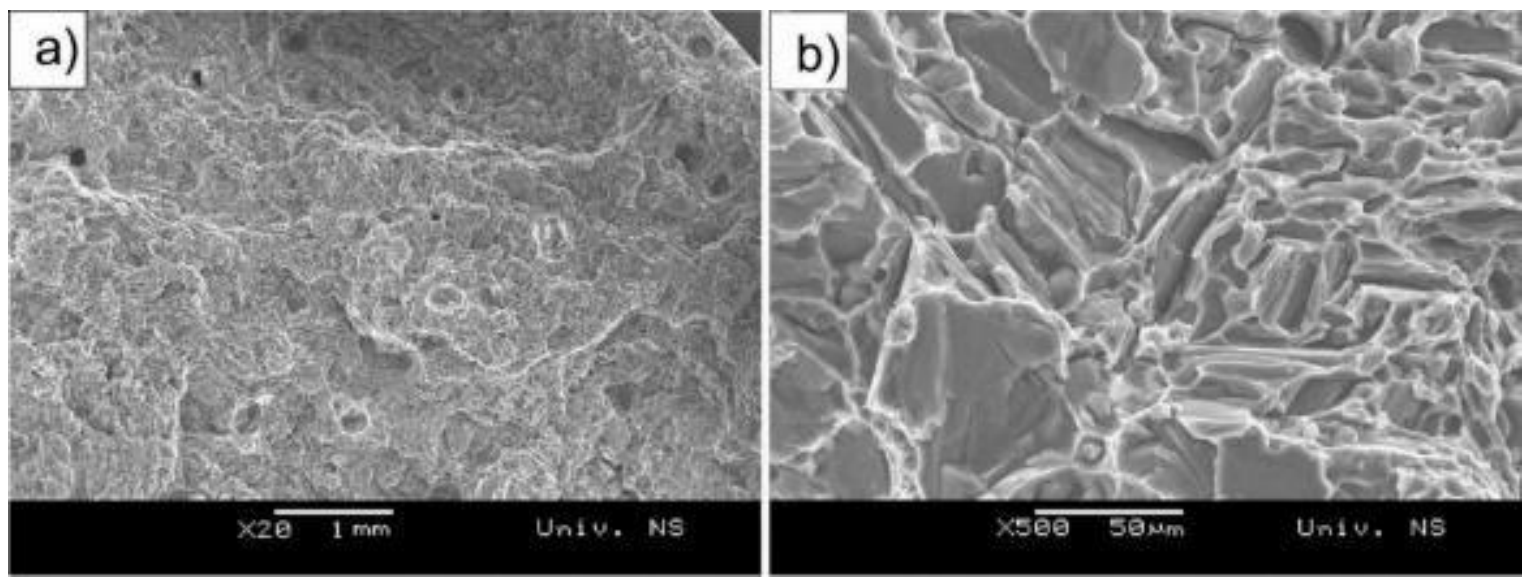

Figure 5: Brittle fracture surface in ASC91 alloy. 

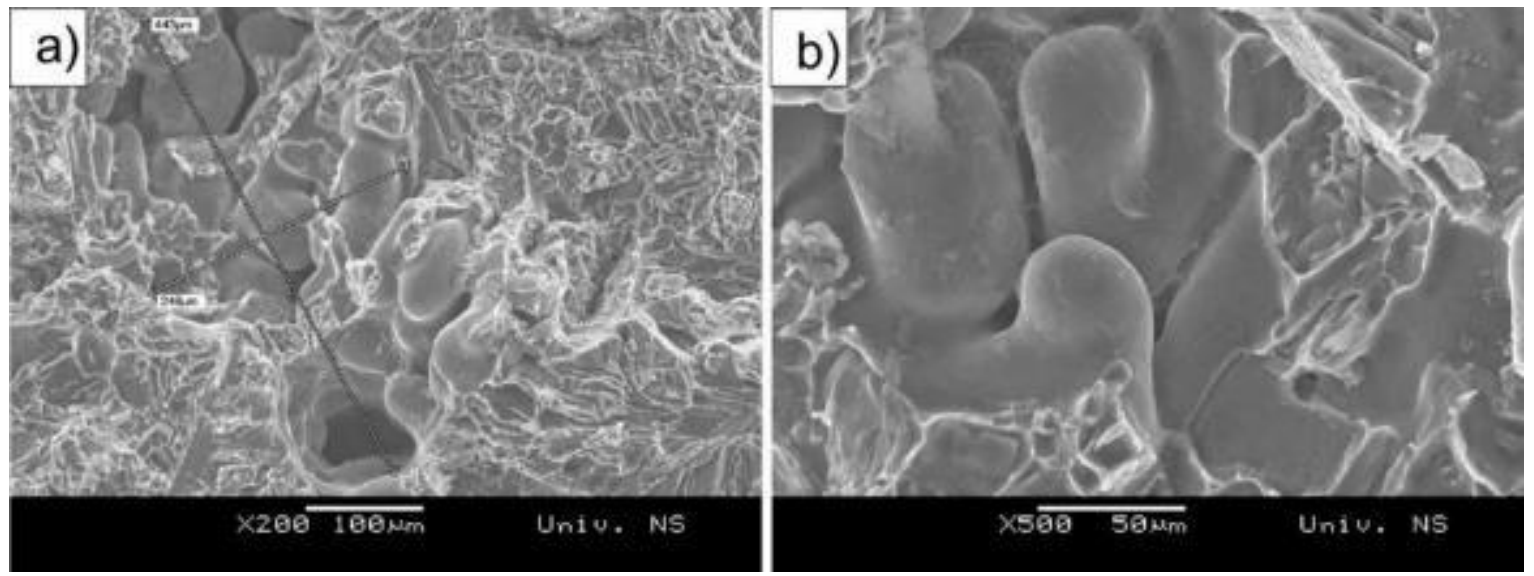

Figure 6: Dendrite microporosity in ASC91 alloy.
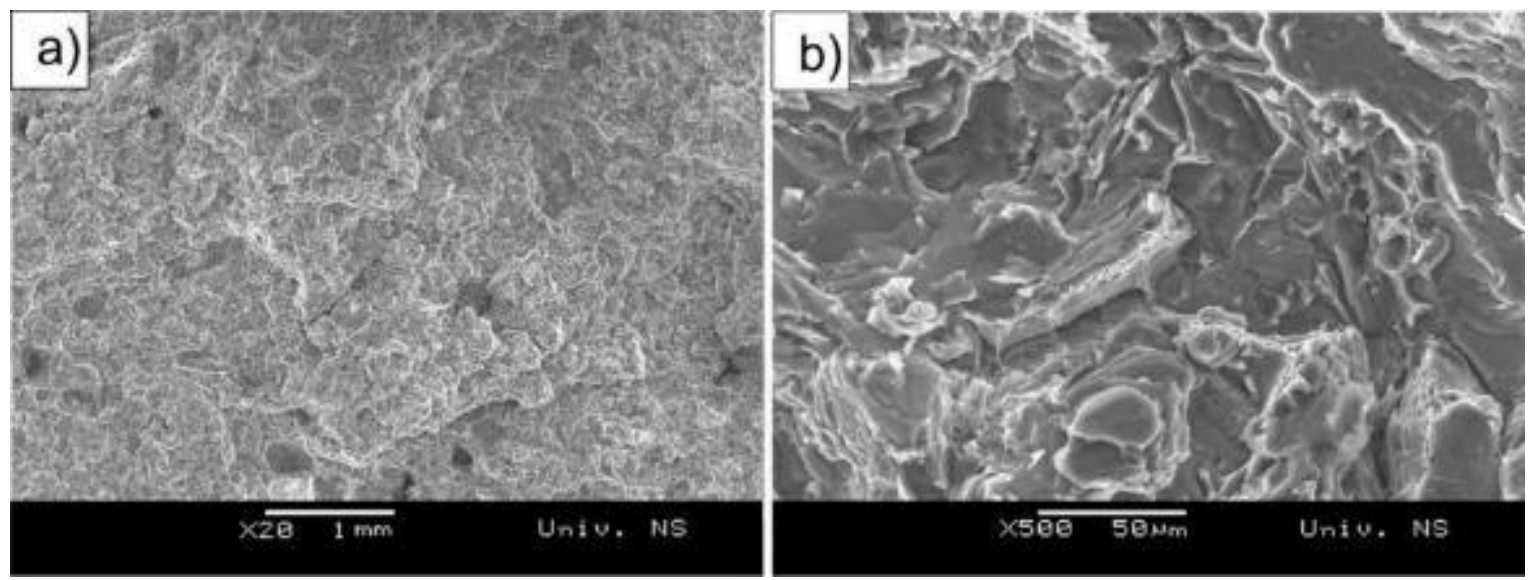

Figure 7: Brittle fracture in ASC93 alloy.
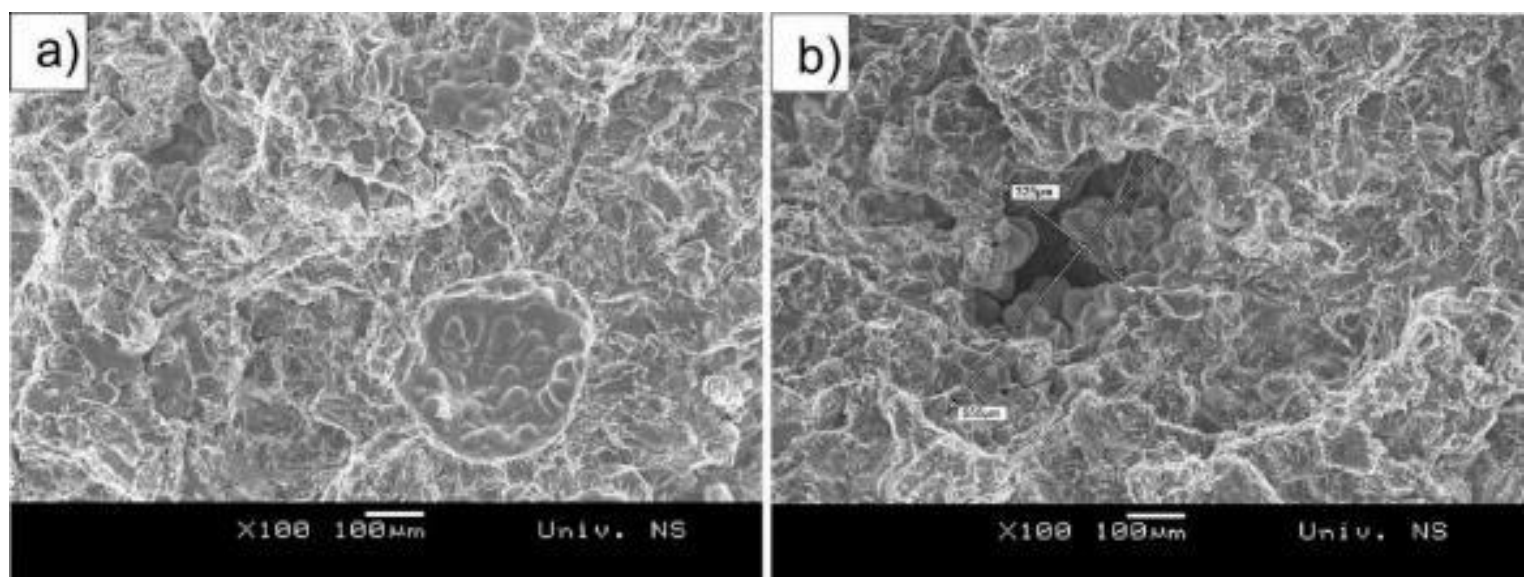

Figure 8: Dendrite microporosity in ASC73 alloy.

The machinability of ASC91 and ASC73 aluminium alloys was assessed by the determination of the resultant force $\left(F_{R}\right)$, maximum roughness height $\left(R_{\max }\right)$, ten-point mean roughness $\left(R_{z}\right)$ in relation to the depth of cut (a) and the feed per tooth $\left(s_{1}\right)$. The experimental results are presented in Table 8 . By the application of regression analysis, dependence equations for $F_{R}, R_{\max }$ and $R_{z}$ were obtained in relation to the depth of cut and the feed per tooth, Eqs. (9-14). Eqs. (9-11) refer to ASC91, while Eqs. (12-14) refer to ASC73 alloy.

$$
\begin{aligned}
& F_{R}=582.16734 \cdot s_{1}^{0.34556} \cdot a^{1.02371} \\
& R_{z}=86.70778 \cdot s_{1}^{1.40238} \cdot a^{0.04471} \\
& R_{\max }=129.67887 \cdot s_{1}^{1.34334} \cdot a^{-0.13643}
\end{aligned}
$$




$$
\begin{aligned}
& F_{R}=343.34555 \cdot s_{1}^{012855} \cdot a^{05544} \\
& R_{z}=34.75465 \cdot s_{1}{ }^{0.83878} \cdot a^{0.15003} \\
& R_{\max }=41.86312 \cdot s_{1}^{0.82446} \cdot a^{0.0884}
\end{aligned}
$$

An analysis of the Eqs.(9-14) shows that the most influential parameter on $F_{R}$ is the depth of cut, while the most influential parameter on $\mathrm{R}_{\mathrm{z}}$ and $\mathrm{R}_{\max }$ is the feed per tooth.

Table 8: Experimental results.

\begin{tabular}{|c|c|c|c|c|c|c|c|c|}
\hline \multirow{2}{*}{ No. } & \multicolumn{2}{|c|}{ Machining parameters } & \multicolumn{3}{|c|}{ ASC91 } & \multicolumn{3}{c|}{ ASC73 } \\
\cline { 2 - 9 } & $\mathrm{s} 1[\mathrm{~mm} / \mathrm{t}]$ & $\begin{array}{c}\mathrm{a} \\
{[\mathrm{mm}]}\end{array}$ & $\begin{array}{c}\mathrm{FR} \\
{[\mathrm{N}]}\end{array}$ & $\begin{array}{c}\mathrm{Rz} \\
{[\mu \mathrm{m}]}\end{array}$ & $\begin{array}{c}\text { Rmax } \\
{[\mu \mathrm{m}]}\end{array}$ & $\begin{array}{c}\text { FR } \\
{[\mathrm{N}]}\end{array}$ & $\begin{array}{c}\text { Rz } \\
{[\mu \mathrm{m}]}\end{array}$ & $\begin{array}{c}\text { Rmax } \\
{[\mu \mathrm{m}]}\end{array}$ \\
\hline 1 & 0.1125 & 1 & 305 & 3.57 & 4.62 & 248 & 5.67 & 7.12 \\
\hline 2 & 0.285 & 1 & 354 & 14.53 & 19.92 & 282 & 14.76 & 16.84 \\
\hline 3 & 0.1125 & 2 & 522 & 4.07 & 5.22 & 368 & 7.51 & 8.32 \\
\hline 4 & 0.285 & 2 & 855 & 13.56 & 14.71 & 411 & 13.72 & 16.29 \\
\hline 5 & 0.178 & 1.41 & 471 & 8.13 & 17.38 & 377 & 7.8 & 10.94 \\
\hline 6 & 0.178 & 1.41 & 469 & 8.43 & 17.86 & 351 & 7.82 & 10.4 \\
\hline 7 & 0.178 & 1.41 & 446 & 9.08 & 15.34 & 342 & 7.72 & 8.55 \\
\hline 8 & 0.178 & 1.41 & 415 & 8.45 & 15.52 & 353 & 7.72 & 9.02 \\
\hline
\end{tabular}

The charts of resultant force $\left(F_{R}\right)$, maximum roughness height $\left(R_{\max }\right)$ and ten-point mean roughness $\left(\mathrm{R}_{\mathrm{z}}\right)$ in relation to the depth of cut (a) and the feed per tooth $\left(\mathrm{s}_{1}\right)$ are shown in Figures. $9-11$. These charts are obtained by the application of Eq. (9-14) and setting the depth of cut or the feed per tooth at their medium value, as a constant.

From Figure 9, it can be seen that the resultant forces of the ASC91 alloy milling are considerably higher than those of the ASC73 alloy. As the depth of cut and the feed per tooth are higher, the difference in the resultant force increases. The resultant force in the ASC73 alloy is $11 \%$ lower at $1 \mathrm{~mm}$ depth of cut, and $62 \%$ lower at $2 \mathrm{~mm}$ depth of cut, compared to the ASC91. However, if the feed per tooth is varied, the corresponding differences are 22 to $47 \%$, if the feed per tooth is increased from 0.112 to $0.285 \mathrm{~mm} / \mathrm{t}$. The tenpoint mean roughness $\left(R_{z}\right)$ in relation to the depth of cut and the feed per tooth is shown in Figure 10. It can be seen that $\mathrm{R}_{\mathrm{z}}$ is lower in the ASC91 alloy over the whole range of the depth of cut values. However, the differences are relatively small. On the other hand, $\mathrm{R}_{\mathrm{z}}$ to the feed per tooth trend lines intersect, which means that up to around $0.21 \mathrm{~mm} / \mathrm{t}, \mathrm{R}_{\mathrm{z}}$ of ASC73 is higher, while over that feed per tooth value, ASC91 $\mathrm{R}_{\mathrm{z}}$ is higher, Figure 10b. That means that at high feeds per tooth, a lower $R_{z}$ is obtained with the ASC73 alloy and vice versa.

The maximum roughness $\left(R_{\max }\right)$ versus the depth of cut and the feed per tooth is shown in Figure 11. The difference in the ASC91 and ASC73 maximum roughness trend lines orientation is plotted against the depth of cut. Namely, ASC91 $R_{\max }$ decreases as the depth of cut increases, while ASC73 $\mathrm{R}_{\max }$ increases at the same time. Hypothetically, these two trend lines might intersect at higher depths of cut. However, in the given range, $R_{\max }$ of ASC73 is lower than that of the ASC91 alloy. Contrary to this and similarly to the $R_{z}$, $\mathrm{R}_{\max }$ trend lines of the two tested aluminium alloys intersect at around $0.13 \mathrm{~mm} / \mathrm{t}$. At lower feeds per tooth, ASC91 alloy has a marginal advantage; however, at higher feeds per tooth, ASC73 $\mathrm{R}_{\max }$ is lower. The difference in $R_{\max }$ increases as the feed per tooth increases, giving the advantage to the ASC73 alloy at higher machining regimes. 
a)

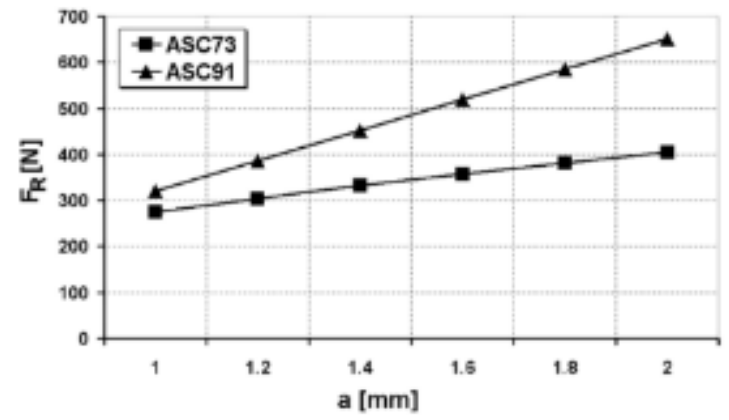

b)

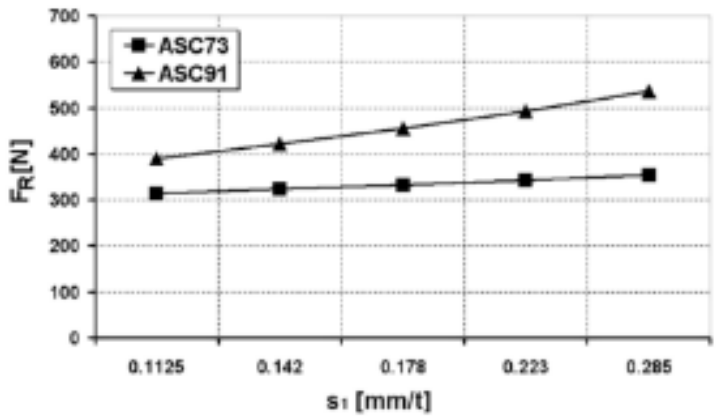

Figure 9: The resultant force versus: a) the depth of cut (feed per tooth set at $0.178 \mathrm{~mm} / \mathrm{t}$ ); b) feed per tooth (the depth of

a)

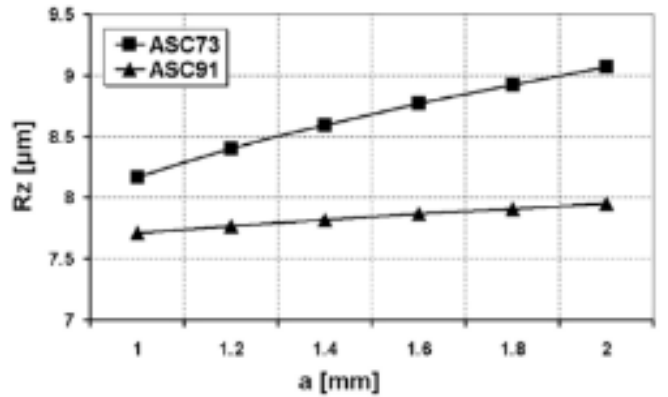

b)

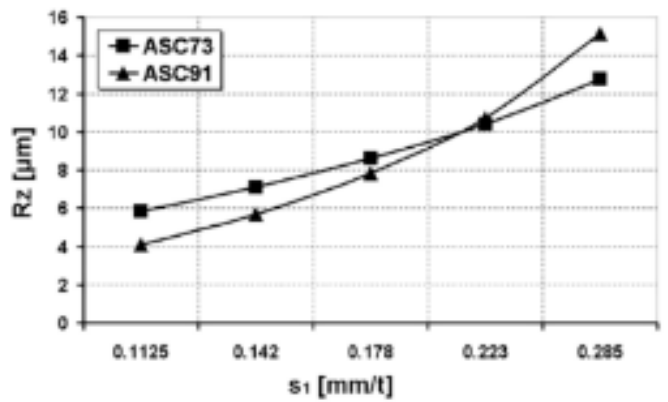

cut set at $1.41 \mathrm{~mm}$ ).

Figure 10: The ten-point mean roughness (Rz) versus: a) the depth of cut (feed per tooth set at $0.178 \mathrm{~mm} / \mathrm{t}$ ); b) feed per

a)

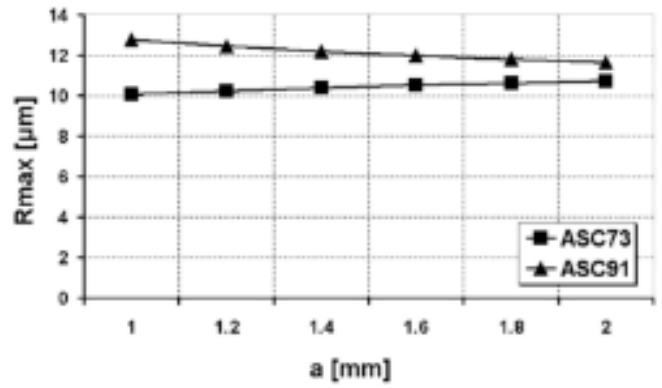

b )

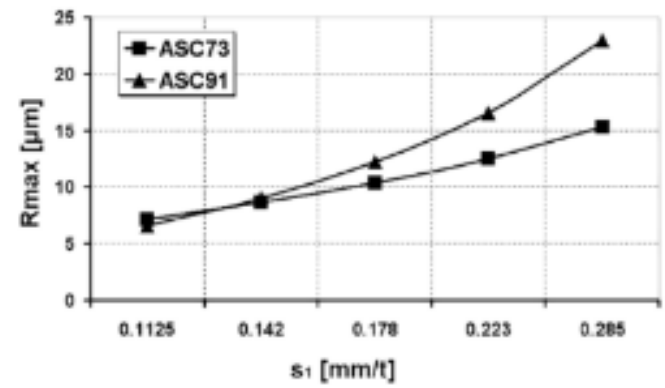

tooth (the depth of cut set at $1.41 \mathrm{~mm}$ ).

Figure 11: The maximum roughness (Rmax) versus: a) the depth of cut (feed per tooth set at $0.178 \mathrm{~mm} / \mathrm{t}$ ); $\mathrm{b}$ ) feed per tooth (the depth of cut set at $1.41 \mathrm{~mm}$ ).

\section{DISCUSSION}

In this paper, the tensile properties (proof strength, ultimate tensile strength, elongation and modulus of elasticity), fatigue performance, microstructure and machinability of two as-cast aluminium alloys were examined. The aim was to determine if ASC91 could be replaced with ASC73 aluminium alloy, with presumably improved machinability due to lower silicon content and retained mechanical properties due to a higher copper content. It was found that, ASC91 has better tensile properties compared to ASC73 alloy, in spite of the increased copper content in ASC73 alloy. The lower tensile properties of ASC73 might be correlated to the lower SML $[15,16]$, reduced amount of eutectic, script appearance of eutectic, and due to the increased, "blocky" appearance of intermetallic phases [17]. However, lower tensile properties are partially outweighed by fatigue performance, where a component made of ASC73 alloy has marginally higher life expectancy, but, higher variations in life expectancy as well. Matching the fatigue properties of ASC73 could be attributed to 
the lower SDAS which gives a better pore distribution [18] and finer eutectic microstructure [19], as well as to the higher amount of ductile $\alpha$-solid solution matrix which prolongs the first step of fatigue crack propagation before the final tearing in the eutectic [20].

On the other hand, machinability of as-cast ASC73 is higher than that of as-cast ASC91, both in terms of resultant force and roughness parameters. This kind of behaviour was expected due to a lower amount of eutectic silicon, which causes tool abrasion wear and decreases machinability [3]. The results of roughness parameters may vary in relation to the feed per tooth, as the $\mathrm{R}_{\mathrm{z}}$ of ASC73 is slightly higher than that of ASC91 at the feed per tooth of $0.178 \mathrm{~mm} / \mathrm{t}$. At a different feed per tooth, exceeding $0.21 \mathrm{~mm} / \mathrm{t}$, a decreased $R_{z}$ is obtained in ASC73. This is supported by the finding that the most influential parameter on $R_{z}$ and $R_{\max }$ is the feed per tooth (see Eqs. 9-14), which determines the trend observed in the $R_{z}$ and $R_{\max }$ versus the depth of cut charts, Figures. 10 and 11. That means, at increased feeds per tooth, over $0.21 \mathrm{~mm} / \mathrm{t}$, the maximum roughness $\left(\mathrm{R}_{\max }\right)$ and the ten-point mean roughness $\left(\mathrm{R}_{\mathrm{z}}\right)$ is lower in ASC73 compared to the ASC91 aluminium alloy. Those lower roughness parameters of ASC73 over ASC91, at higher feeds per tooth, might be the result of a microstructure that contains an increased amount of $\alpha$-solid solution. Namely, an increased feed per tooth results in increased resultant force $\left(F_{R}\right)$, due to the strain hardening of the $\alpha$-solid solution in the cutting zone, resulting in lower $R_{\max }$ and $R_{z}$. However, at low feeds per tooth, the $\alpha$-solid solution adheres more to the cutting tool increasing the surface roughness parameters $[1,3,21]$. The resultant force related to the depth of cut and feed per tooth also stresses the higher machinability of ASC73 over ASC91 alloy. More accurately, the resultant force in ASC73 milling at $2 \mathrm{~mm}$ depth of cut equals that of ASC91 alloy at only 1.25 $\mathrm{mm}$ depth of cut, meaning that even at a maximum feed per tooth, the resultant force of ASC73 machining is lower than that of the ASC91 alloy at the lowest feed per tooth. This indicates that ASC73 may be machined with a higher depth of cut and feed per tooth compared to ASC91 alloy, which increases the productivity.

\section{CONCLUSIONS}

In accordance to the presented results, the following conclusions can be drawn:

- The room temperature mechanical properties: modulus of elasticity, proof strength, tensile strength and elongation are all higher in the as-cast ASC91 alloy compared to the as-cast ASC73 alloy. Such behaviour might be attributed to the larger amount of eutectic, higher SML, and to the rounded appearance of the Si particles and intermetallic phases.

- At $130{ }^{\circ} \mathrm{C}$, the fatigue resistance of the ASC73 alloy is marginally higher, but with higher variations as well, compared to ASC91, when tested under fully reversed axial loading using a step test protocol. The fatigue properties of ASC73 could be attributed to the lower SDAS which gives better pore distribution and finer eutectic microstructure, as well as to the higher amount of ductile $\alpha$-solid solution matrix which prolongs the first step of fatigue crack propagation before the final tearing in the eutectic.

- The regression analysis proved that the most influential parameter on resultant force (FR) is the depth of cut, while the most influential parameter on maximum roughness (Rmax) and the ten-point mean roughness $(\mathrm{Rz})$ is the feed per tooth.

- The surface roughness parameters, Rmax and Rz, are lower for the ASC73 alloy than those of the ASC91 alloy, if the feed per tooth is higher than $0.21 \mathrm{~mm} / \mathrm{t}$.

- The resultant force (FR) in face milling is considerably lower for ASC73, compared to the ASC91 alloy in the whole range of cutting parameters tested. Furthermore, the difference in resultant forces increase as higher depths of cut and feeds per tooth are applied.

Overall, the conclusions of this study suggest that the ASC73 alloy is more preferable for industrial application (cylinder head) than the ASC91 alloy in terms of fatigue performance and machinability.

\section{BIBLIOGRAPHY}

[1] DWIVEDI, D. K., SHARMA, A., RAJAN, T. V., "Machining of LM13 and LM28 cast aluminium alloys: Part I", Journal of Materials Processing Technology, v. 196, pp. 197-204, 2008.

[2] PATHAK, J.P., Tiwari S.N., "Chip formation in machining of Al-Si alloy", Indian Foundry Journal, v. 41 pp. 1-8, 1995.

[3] KAMIYA, M., YAKOU, T., SASAKI, T., et al., "Effect of Si content on turning machinability of Al-Si binary alloy castings", Materials Transactions, v.49, pp. 587-592, 2008.

[4] LIU, J., CHOU, Y.K., "On temperatures and tool wear in machining hypereutectic Al-Si alloys with vortex-tube cooling", International Journal of Machine Tools and Manufacture, v. 47, pp. 635-645, 2007. 
[5] YOUN, J. I., KANG, B. I., KO, D. G., et al., "Effects of sonoprocessing on microstructure and mechanical properties of A390 aluminium alloy", International Journal of Cast Metals Research, v. 21, pp. 135-138, 2008.

[6] FENG, H. K., YU, S. R., LI, Y. L., et al., "Effect of ultrasonic treatment on microstructures of hypereutectic Al-Si alloy", Journal of Materials Processing Technology, v. 208, pp. 330-335, 2008.

[7] LU, D. H., JIANG, Y. H., GUAN, G. S., et al., "Refinement of primary Si in hypereutectic Al-Si alloy by electromagnetic stirring", Journal of Materials Processing Technology, v. 189, pp. 13-18, 2007.

[8] ANURADEE, T., MAWIN, S., UMEDA, T., et al., "Grain refinement of primary Si in continuously cast hypereutectic Al-Si alloy by electromagnetic vibration", International Journal of Cast Metals Research, v. 21, pp. 198-202, 2008.

[9] CHANG, J. Y., MOON, I. G., CHOI, C. S., "Refinement of Cast Microstructure of Hypereutectic Al-Si Alloys Through the Addition of Rare Earth Metals", Journal of Materials Science, v. 33, pp. 5015-2023, 1998.

[10] YI, H. K., ZHANG, D., "Morphologies of Si phase and La-rich phase in as-cast hypereutectic Al-SixLa alloys", Materials Letters, v. 57, pp. 2523-2529, 2003.

[11] American Foundry Society, Chart for microstructure control in hypoeutectic aluminum silicon alloys, American Foundry Society, Inc., Des Plaines, Illinois, USA 1990

[12] BOAG, A., HUGHES, A.E., GLENN, A.M. et al., "Corrosion of AA2024-T3 Part I: Localised corrosion of isolated IM particles", Corrosion Science, v. 53, pp. 17-26, 2011.

[13] BELOV, N.A., ESKIN, D.G., AVXENTIEVA, N.N., "Constituent phase diagrams of the Al-Cu-Fe-MgNi-Si system and their application to the analysis of aluminium piston alloys", Acta Materialia, v. 53, pp. 4709-4722, 2005.

[14] KRAL, M.V., "A crystallographic identification of intermetallic phases in Al-Si alloys", Materials Letters, v. 59 pp. 2271-2276, 2005.

[15] HEGDE, S., PRABHU, K.N., "Modification of eutectic silicon in Al-Si alloys", Journal of Materials Science, v. 43, pp. 3009-3027, 2008.

[16] DOBRZANSKI, L.A., MANIARA, R., SOKOLOWSKI, J., et al., "Effect of cooling rate on the solidification behavior of AC AlSi7Cu2 alloy", Journal of Materials Processing Technology, v. 191, pp. 317-320, 2007.

[17] LI, Z., SAMUEL, A.M., SAMUEL, F.H., et al., "Parameters controlling the performance of AA319type alloys Part I. Tensile properties", Materials Science and Engineering, v. 367, pp. 96-110, 2004.

[18] ZHU, X., SHYAM, A., JONES, J.W., et al., "Effects of microstructure and temperature on fatigue behavior of E319-T7 cast aluminum alloy in very long life cycles", International Journal of Fatigue, v. 28, pp. 1566-1571, 2006.

[19] CATON, M.J., JONES, J.W., BOILEAU, J.M., et al., "The effect of solidification rate on the growth of small fatigue cracks in a cast 319-type aluminum alloy", Metallurgical and Materials Transactions A: Physical Metallurgy and Materials Science, v. 30, pp. 3055-3068, 1999.

[20] GALL, K., YANG, N., Horstemeyer, M., et al., "Influence of modified intermetallics and Si particles on fatigue crack paths in a cast A356 Al alloy", Fatigue and Fracture of Engineering Materials and Structures, v. 23, pp. 159-172, 2000.

[21] GRUM, J., KISIN, M., "Influence of microstructure on surface integrity in turning - Part I: The influence of the size of the soft phase in a microstructure on surface-roughness formation", International Journal of Machine Tools and Manufacture, v. 43, pp. 1535-1543, 2003.

\section{ORCID}

Sebastian Balos

https://orcid.org/0000-0002-3828-8500

Dragan Rajnovic

https://orcid.org/0000-0002-5303-4402

Leposava Sidjanin

https://orcid.org/0000-0001-6913-972X

Borislav Savkovic

https://orcid.org/0000-0002-9037-2179

Pavel Kovac

https://orcid.org/0000-0002-5224-4002

Petar Janjatovic

https://orcid.org/0000-0002-3779-9341 